\title{
ON THE LOCALIZED PHYSICAL EXERGY DISAGGREGATION FOR DISSIPATIVE COMPONENT ISOLATION IN THERMOECONOMICS
}

\author{
R. G. Santos ${ }^{\mathrm{a}, \mathrm{b}}$, \\ P. R. Faria ${ }^{a, c}$, \\ I. C. Belisario ${ }^{\text {, }}$ \\ M. A. Barrone ${ }^{a}$, \\ and J. J. C. S. Santos ${ }^{a}$ \\ ${ }^{\mathrm{a}}$ Universidade Federal do Espírito Santo \\ Departamento de Engenharia Mecânica \\ Bairro Goiabeiras \\ CP. 29075910, Vitória, Espírito Santo, Brasil \\ rodrigo.guedes@ifes.edu.br \\ pedro.faria@ifes.edu.br \\ mabacz@gmail.com \\ jjcssantos@yahoo.com.br \\ ${ }^{b}$ Instituto Federal do Espírito Santo \\ Coordenadoria de Mecânica \\ Bairro Jucutuquara
}

CP. 29040780, Vitória, Espírito Santo, Brasil 'Instituto Federal do Espírito Santo

Coordenadoria de Ferrovias

Bairro Itacibá

CP. 29150410, Cariacica, Espírito Santo, Brasil

${ }^{\mathrm{d} I n s t i t u t o}$ Federal do Espírito Santo

Coordenadoria de relações institucionais e

extensão comunitária

Bairro Litorâneo

CP. 29932540, São Mateus, Espírito Santo,

Brasil

igor.belisario@ifes.edu.br

Received: Dec 07, 2020

Revised: Dec 12, 2020

Accepted: Dec 13, 2020

\begin{abstract}
Thermoeconomics is a discipline that connects Thermodynamics and Economics concepts, usually used for rational cost allocation to the final products of a thermal plant, by means of a model that describes the cost formation process of the overall system. Generally, exergy or monetary costs of the external resources are distributed to the final products. Exergy is the thermodynamic magnitude used in thermoeconomics and the physical exergy disaggregation has been introduced in thermoeconomics as alternatives for the isolation of the dissipative components and residues allocation. For plants with dissipative equipment, such as condenser or valve, the productive diagram, based on total exergy (E Model), need to merge this dissipative equipment with other productive components. In order to isolate the condenser, the productive diagram must use, at least, the H\&S Model and to isolate the valve, the UFS Model has to be considered. Both disaggregation models greatly increase the thermoeconomic modeling complexity. Bearing this in mind, this work aims to evaluate the advantages of combining the $\mathrm{E}$ Model with these other models in order to adequately isolate the dissipative equipment. The plants studied herein are two different steam turbine cogeneration systems, with dissipative components (condenser or valve). The different monetary and exergy unit costs obtained for the two final products of each plant are compared and analyzed. The results show that localized physical exergy disaggregation for dissipative component isolation in thermoeconomics is feasible, since it reduces the complexity of the productive structure and is also consistent from the point of view of thermodynamics.
\end{abstract}

Keywords: cost allocation; dissipative components; physical exergy disaggregation; thermoeconomics

\section{NOMENCLATURE}

c Monetary Unit Cost, $\$ / \mathrm{kWh}$

E Exergy flow, $\mathrm{kW}$

$\mathrm{H}$ Enthalpy flow, $\mathrm{kW}$

$\mathrm{k} \quad$ Exergetic Unit Cost, $\mathrm{kW} / \mathrm{kW}$

$\mathrm{m}$ mass flow, $\mathrm{kg} / \mathrm{s}$

P Power, $\mathrm{kW}$

Q Heat Exergy, kW

$\mathrm{S} \quad$ Entropy flow, $\mathrm{kW}$

Y Generic Productive Flow, kW

Z Hourly Cost, $\$ / \mathrm{h}$

$\begin{array}{ll}\text { Subscripts } \\ \text { C } & \text { condenser } \\ \text { F } & \text { Fuel } \\ \text { HP } & \text { high pressure } \\ \text { in } & \text { inlet } \\ \text { i,j } & \text { index for productive components } \\ \text { LP } & \text { low pressure } \\ \text { N } & \text { net power } \\ \text { out } & \text { outlet } \\ \text { SG } & \text { steam generator }\end{array}$


U useful heat

\section{INTRODUCTION}

Thermoeconomics can be considered a science which, by connecting Thermodynamics and Economics, provides tools to solve problems in complex energy systems that can hardly or not be solved using conventional energy analysis techniques based on the First Law of Thermodynamics (mass and energy balance), as for instance a rational price assessment to the products of a plant based on physical criteria (Erlach et al., 1999). Most analysts agree that exergy, instead of enthalpy only, is the most adequate thermodynamic property to associate with cost (originally an economic property) since it contains information from the Second Law of Thermodynamics and accounts for energy quality. An exergy analysis locates and quantifies the irreversibilities of the processes and systems (Valero et al., 2006; Dincer and Rosen, 2013).

Sometimes, under a thermoeconomic analysis, it is necessary to consider the components as a group of subsystems and/or the exergy flows consisting of several components, i.e., thermal and mechanical components, because the more disaggregated is the system the more accurate are the results (Torres et al., 1996). Depending on the type of analysis, different levels of accuracy of the results are required, i.e., each thermoeconomic analysis requires a specific disaggregation level of the components and flows (Valero et al., 2006). For local optimization and diagnosis, for instance, total disaggregation of the components of the system is generally required. In agreement with (Lozano e Valero, 1993), the deeper and more detailed the disaggregation is, the clearer the interpretation of the obtained costs will be and the wider the catalog of applications to theoretical and practical problems.

In the last years, new kinds of physical exergy disaggregation have been introduced in thermoeconomics as consistent alternatives in order to disaggregate the dissipative components of the systems and to allocate the cost of the residues to the final products. In the case of condensers, a solution was proposed by Frangopoulos (1983) and Frangopoulos (1987) to define product and input. It uses a fictitious flow called negentropy, which is considered the product of the condenser, and exergy, as an input. In this way, the condenser becomes the negentropy supplier for the system. Some researchers have found that this fictitious flow generates inconsistent results when used in conjunction with total exergy (Santos et al., 2006; Santos et al., 2008; Santos et al., 2009). These inconsistent results were overcome by H\&S Model which defines the productive structure by disaggregating the physical exergy into enthalpic and entropic components. This kind of physical exergy disaggregation was introduced by Santos et al., (2006) and it was proposed as an alternative exergy disaggregation methodology to isolate condensers. The total physical exergy is defined as the difference between the enthalpic and entropic components. Another important work proposed to deal rationally with residues and dissipative equipment was proposed by Lazzaretto and Tsatsaronis (2006), called The Specific Exergy Costing (SPECO).

Despite the H\&S disaggregation defines condenser input and product, the same it is not possible for valves, as identified by Lourenço (2011). One proposed solution for the valve is the use of thermal and mechanical exergy disaggregation with the calculation methodology presented by Tsatsaronis (1993) and Morosuk and Tsatsaronis (2008). However, these methodologies are arbitrary and the disaggregation does not define input and product for refrigeration cycle valves and depend on the state of the fluid at the valve inlet (Faria, 2014a). Thus, Lourenço (2011) looking for an alternative for disaggregation of valves, presented the UFS Model that utilizes physical exergy disaggregation into internal energy $(U)$, work flow $(F)$ and entropic term $(S)$. It was the first methodology of exergy disaggregation capable of consistently isolating valves. This level disaggregates the enthalpic term in internal energy and work flow and maintains the entropic one. Nevertheless, when the thermoeconomist chooses one of these methodologies, the productive diagrams greatly increase the complexity. At this point, an approach to reduce this complexity in thermoeconomics is needed.

This paper aims to evaluate the possibility and advantages of localized physical exergy disaggregation for dissipative component isolation in thermoeconomics, i.e., combine E Model with a localized exergy disaggregation. To answer these and other questions related to the combination among different models in thermoeconomics, three models and their respective combinations is herein used in two different steam turbine cogeneration systems, with dissipative components (condenser or valve). The different monetary and exergy unit costs obtained for the two final products of each plant are compared and analyzed.

\section{THERMOECONOMIC MODELING}

In order to determine the exergy and/or monetary costs of the external resources' allocation to the final products and, consequently, for the assessment of the exergetic and the monetary unit cost of both internal flows and final products, a thermoeconomic model must be used. This model could be defined as a set of cost equations that describes mathematically the cost formation process of the system final products. A thermoeconomic model should be performed by using Eq. (1) and (2).

All thermoeconomic methodologies agree that the productive purpose of the subsystems need to be 
defined, as well as the distribution of the external resources throughout the system, which can be represented by means of a diagram as shown in Fig. 27. The solution of this cost set, Eq. (1), is the monetary unit costs of each internal flow and each final product. The monetary unit cost of a flow is the amount of external monetary unit required to obtain one unit of this flow, i.e., it is a measure of the economic efficiency of the production process when producing this flow (Valero et al., 2006).

$$
\sum\left(c_{\text {out }} \cdot Y_{\text {out }}\right)-\sum\left(c_{\text {in }} \cdot Y_{\text {in }}\right)=c_{F} \cdot E_{F}+Z
$$

$\mathrm{Z}$ represents the external hourly cost of the subsystem due to the capital cost, operation and maintenance cost of each subsystem (in $\$ / \mathrm{h}$ ); $\mathrm{c}_{\mathrm{F}}$ is a known market unit cost of the external fuel exergy (in $\$ / \mathrm{kWh}$ ) and $\mathrm{E}_{\mathrm{F}}$ is the amount of the plant external fuel exergy consumption (in $\mathrm{kW}$ ). $\mathrm{c}_{\text {out }}$ and $\mathrm{c}_{\text {in }}$ are unknown variables representing the monetary unit cost of the internal flows at the outlet and at the inlet of each subsystem (in $\$ / k W h$ ), respectively and $Y_{\text {out }}$ and $Y_{\text {in }}$ represent the generic internal flows (in $\mathrm{kW}$ ) at the outlet and at the inlet of each subsystem, respectively, which can be assessed using any thermodynamic magnitude, such as, power $(\mathrm{P})$, heat $(\mathrm{Q})$, total exergy $(E)$, entropic $(\mathrm{S})$, enthalpic $(\mathrm{H})$, internal energy $(\mathrm{U})$ and flow work (F) components, etc.

In order to formulate the cost equation balances to provide the exergetic unit cost $\left(k_{\text {out }}\right.$ and $\left.k_{\text {in }}\right)$ of each internal flow and final products of the diagram, Eq. (2) is obtained by modifying Eq. (1).

$$
\sum\left(k_{\text {out }} \cdot Y_{\text {out }}\right)-\sum\left(k_{\text {in }} \cdot Y_{\text {in }}\right)=k_{F} \cdot E_{F}
$$

The exergetic unit cost of a flow (in $\mathrm{kW} / \mathrm{kW}$ ) is the amount of exergy required to obtain one exergy unit of this flow and it is a measure of the thermodynamic efficiency of the production process generating this flow (Valero et al., 2006). In Eq. (2), the hourly cost of the subsystem due to the capital cost, operation and maintenance must be zero $(Z=0)$ and the monetary unit cost of the external fuel exergy is replaced by the exergetic unit cost of the external fuel exergy, which is $1 \mathrm{~kW} / \mathrm{kW}$, because there is no exergy destruction before the productive process is performed (Valero et al., 2006).

\section{CASE STUDY}

The steam turbine cogeneration plants allow leading with working fluid modelled as real fluid and incorporate a dissipative component, such as a condenser or a bypass valve, in the system studied. All cogeneration systems were modelled considering actual cycle.

\section{Physical Structures}

Figure 1 represents the physical structures of two different steam turbine cogeneration plants studied. The first, Fig. 1(a), is an Extraction Condensing Steam Turbine (ECT). A Backpressure Steam Turbine Cogeneration Plant with a Bypass Valve (VBPT) is the second, Fig. 1(b). Both boilers operate under the same parameters (pressures, temperatures, and thermal efficiencies). Both structures use the same natural gas composition as fuel. However, the steam mass flows produced are different. In Fig. 1(b), the steam mass flows expanded in both turbine and valve are the same. The net power produced are, respectively, 3,963 kW and $964 \mathrm{~kW}$ for the ECT and VBPT. The steam pressures to the processes are similar and the parameters (pressure and temperature) of the condensate returning the process are also the same. The useful heat (in exergy basis) are $1,881 \mathrm{~kW}$ and $4,4121 \mathrm{~kW}$, respectively, for the ECT and VBPT. In Fig. 1(a), the condenser pressure is $5.62 \mathrm{kPa}$. More details can be found in the master degree dissertation of Faria (2014a).

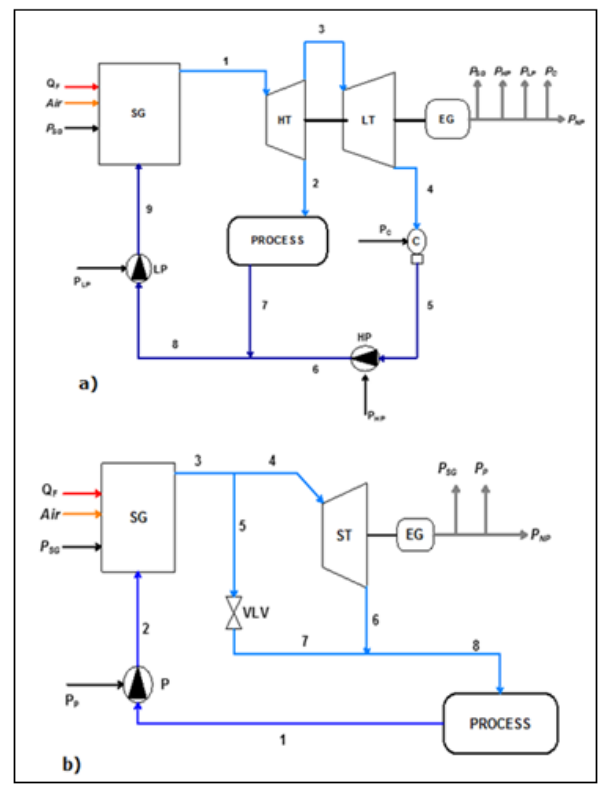

Figure 1. Physical Structures of the Cogeneration Systems with a) Extraction Condensing Steam Turbine and b) with Back Pressure Steam Turbine and bypass valve. Available from Faria et al., (2014b)

\section{Productive Structure for the system with Extraction Condensing Steam Turbine}

Figure 2 shows the productive diagram of the system with Extraction Condensing Steam Turbine using the E Model which uses total exergy flows (E) as the thermodynamic magnitude to define the productive structure. This Model cannot define a product for the condenser $(\mathrm{C})$ and consequently cannot isolate it. Therefore, this component is allocated together with the low turbine (LT) once as most 
analysts agree that the vacuum at the condenser allows increasing the expansion process at turbine for additional power production. The only external resource of the system is fuel exergy $\left(\mathrm{Q}_{\mathrm{F}}\right)$ due to the natural gas consumption. The final products are mechanical net power $\left(\mathrm{P}_{\mathrm{N}}\right)$ and useful heat exergy $\left(\mathrm{Q}_{\mathrm{U}}\right)$. The rectangles are the real units (or subsystems) that represent the actual equipment of the system. The rhombus and the circles are fictitious units called junction $\left(\mathrm{J}_{\mathrm{E}}\right)$ and bifurcations $\left(\mathrm{B}_{\mathrm{E}}\right)$, respectively. Each productive unit of Fig. 2 has inlet and outlet arrows, that represent its fuel (or resource) and products, respectively. The reference temperature and pressure are fixed at $25^{\circ} \mathrm{C}$ and $101.32 \mathrm{kPa}$, respectively.

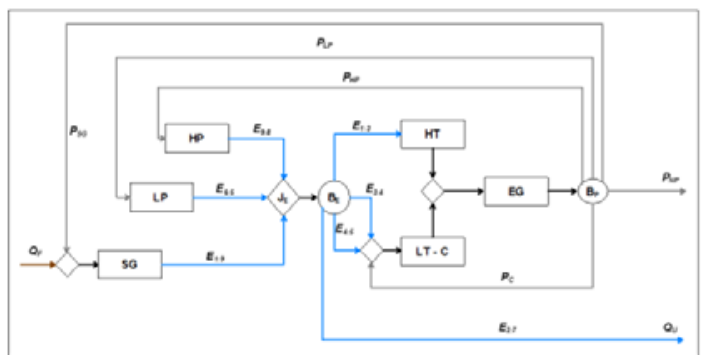

Figure 2. Productive Structure for the System with Extraction Condensing Steam Turbine using E Model. Available from Faria et al., (2014b)

Figure 3 represents the productive diagram for the Extraction Condensing Steam Turbine using the H\&S Model (Santos et al., 2006) in which the flows are defined using the variation of the enthalpic $\left(\mathrm{H}_{\mathrm{i}: \mathrm{j}}\right)$ and entropic $\left(\mathrm{S}_{\mathrm{i}: \mathrm{j}}\right)$ components of the exergy between two physical states, i and j, respectively. It was the first exergy disaggregation methodology capable to isolate (without inconsistencies) condensers in the productive diagrams.

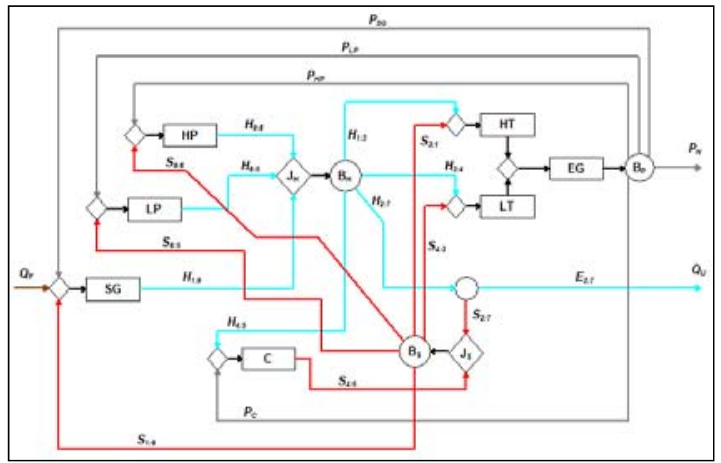

Figure 3. Productive Structure for the System with Extraction Condensing Steam Turbine using H\&S Model Available from Faria et al., (2014b)

As already mentioned, the $\mathrm{E}$ Model is not able to define a product to the condenser. On the other hand, the H\&S Model can define a product and consequently isolate this equipment. Nonetheless, it considerably increases the complexity of the productive structure. At this point, the idea of localized physical exergy disaggregation arises proposing to combine these methodologies in the productive structure. In Fig. 4, the $\mathrm{E}$ Model is being used in all components, except in the condenser where the H\&S Model must be used. Hence, the complexity is reduced.

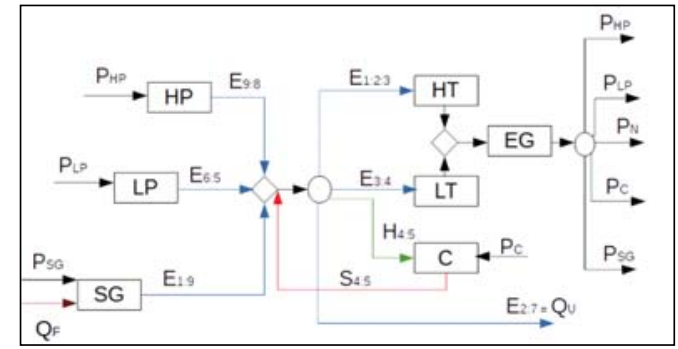

Figure 4. Productive Structure for the system with Extraction Condensing Steam Turbine using E Model and Localized H\&S Model.

\section{Productive Structure for the system with Back Pressure Steam Turbine and Bypass Valve}

In the Bypass Valve and Backpressure Steam Turbine Cogeneration Plant, the E Model must allocate the valve together with another subsystem. Firstly, the valve was allocated with the turbine (ST-VLV) and then with the process (Proc-VLV). These two forms follow the idea that if it is impossible to disaggregate the dissipative equipment, it should be allocated together with some productive equipment. Figures 5(a) and 5(b) show these two ways to allocate the valve using the productive structure according to E Model.

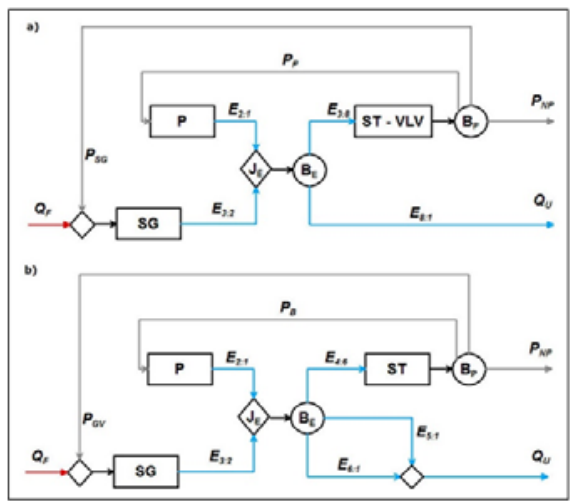

Figure 5. Productive Structure for the System with Back Pressure Steam Turbine and bypass valve using the E Model (a) ST-VLV and (b) Proc-VLV. Available from Faria et al., (2014b)

Figure 6 shows the thermoeconomic methodology capable of defining a product for the valve and isolate it in the productive structure. This model (UFS Model) 
utilizes physical exergy disaggregated into internal energy (U), work flow (F) and entropic term (S) according to Lourenço et al. (2011).

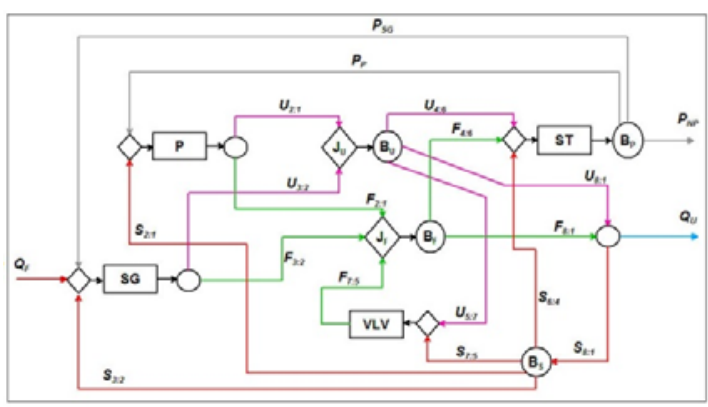

Figure 6. Productive Structure for the System with Back Pressure Steam Turbine and bypass valve using the UFS Model. Available from Faria et al., (2014b)

The E Model also is not able to define a product to the valve. On the other side, the UFS Model can define a product and consequently isolate this dissipative. However, it considerably increases the complexity of the productive structure. At this point, the idea of localized physical exergy disaggregation arises again proposing to combine these methodologies in productive structure. In Fig. 7, the E Model is being used in all components, except in the valve where the UFS Model must be used. Thus, the complexity of productive structure is reduced.

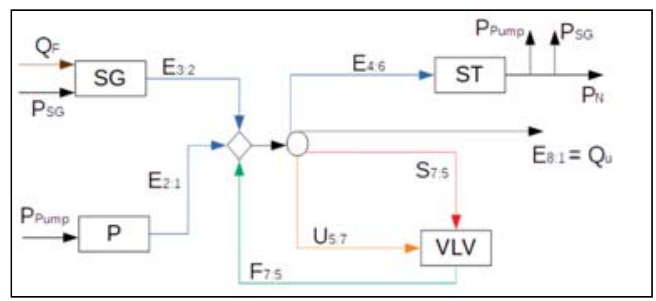

Figure 7. Productive Structure for the system with Back Pressure Steam Turbine and bypass valve using E Model and Localized UFS Model.

\section{RESULTS AND DISCUSSION}

Figures 8 and 9 compare the exergetic and the monetary unit costs, respectively, for the Condensing Extraction Steam Turbine Cogeneration Plant. The E Model cannot isolate the condenser in the productive structure and allocates it together with the turbine. Consequently, it overcharges the unit cost of power in detriment of the unit cost of heat. Comparing the H\&S Model, that isolates this dissipative component, with E Model the exergetic unit cost of power increases $1.15 \%$ and the exergetic unit cost of heat decreases $3.81 \%$. In addition, when the comparison is between $\mathrm{H} \& \mathrm{~S}$ Model and the combination of E Model with H\&S Model, the exergetic unit cost of power decreases by $0.16 \%$ and the exergetic unit cost of heat increases $0.5 \%$.

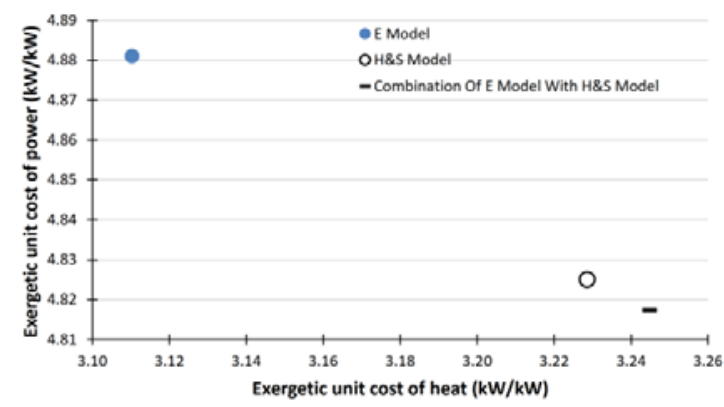

Figure 8. Exergetic unit cost for the final products obtained by using different models for the system with Extraction Condensing Steam Turbine.

Figure 9 shows the monetary unit cost for the analyzed plant. In this case, from the E Model, the exergetic unit cost of power increases $1.28 \%$ and the exergetic unit cost of heat decreases $4.61 \%$. However, when the comparison is between H\&S Model and the combination of $\mathrm{E}$ Model with H\&S Model, the exergetic unit cost of power decreases $0.18 \%$ and the exergetic unit cost of heat increases $0.60 \%$.

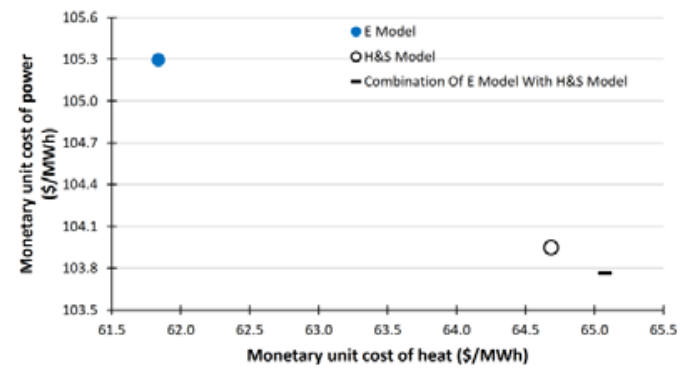

Figure 9. Monetary unit cost for the final products obtained by using different models for the system with Extraction Condensing Steam Turbine.

Figures 10 and 11 show the exergetic and monetary unit costs for the Bypass Valve and Backpressure Steam Turbine Cogeneration Plant. As long as the E Model cannot isolate the valve in the productive structure, it can be allocated together with the turbine (ST-VLV), overcharging the unit cost of power in detriment of the unit cost of heat, or it can be allocated together with the process (Proc-VLV), overcharging the unit cost of heat in detriment of the unit cost of power. Figure 10 shows that UFS Model is the only one able to isolate the valve in the productive structure of the Bypass Valve and Backpressure Steam Turbine Cogeneration Plant. In this case, from the E Model, when the valve is allocated together with the turbine (ST-VLV), the exergetic unit cost of power increases $25.62 \%$ and the exergetic unit cost of heat decreases $15.24 \%$ and when the valve is allocated together with 
the process (Proc-VLV), the exergetic unit cost of heat increases $8.59 \%$ and the exergetic unit cost of power decreases $32.37 \%$. Nevertheless, when the comparison is between UFS Model and the Combination of $\mathrm{E}$ Model with UFS Model, the exergetic unit cost of power decreases $9.65 \%$ and the exergetic unit cost of heat increases $3.27 \%$

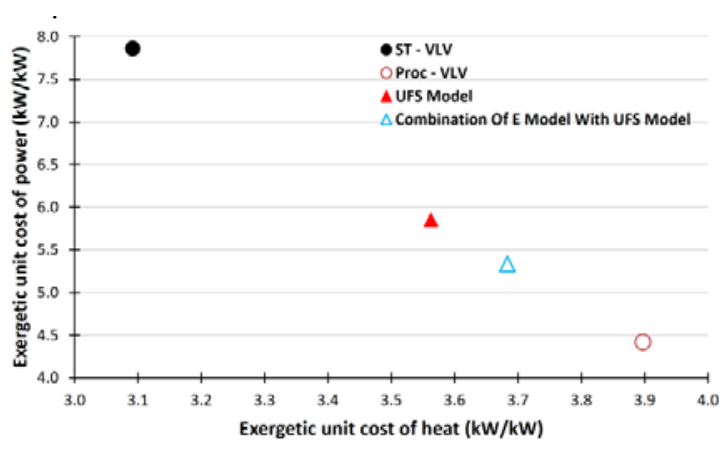

Figure 10. Exergetic unit cost for the final products obtained by using different models for the system with Back Pressure Steam Turbine and bypass valve.

Figure 11 shows the monetary unit cost for the analyzed plant and in this case, from the ST-VLV, the monetary unit cost of power increases $24.27 \%$ and the monetary unit cost of heat decreases $15.30 \%$, when compared with UFS Model. Moreover, for Proc-VLV analysis, the unit cost of heat increases $8.63 \%$ and the exergetic unit cost of power decreases $29.54 \%$. However, when the comparison is between the UFS Model and the Combination of E Model with UFS Model, the unit cost of power decreases $8.96 \%$ and the exergetic unit cost of heat increases $3.29 \%$.

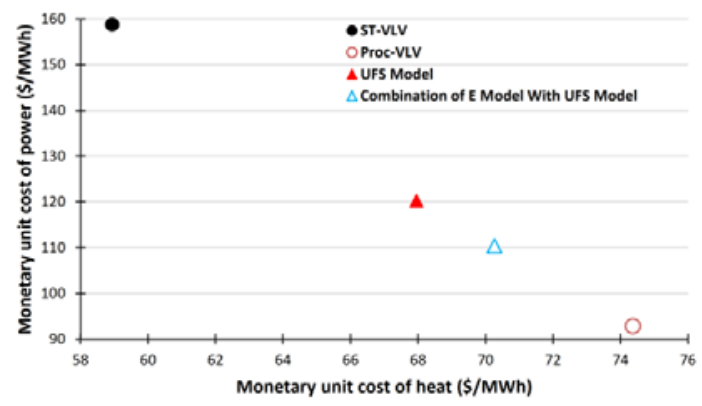

Figure 11. Monetary unit cost for the final products obtained by using different models for the system with Back Pressure Steam Turbine and bypass valve.

\section{CONCLUSIONS}

The localized physical exergy disaggregation was presented and applied in two cogeneration plants with dissipative components and the results are compared with some known methodologies.
The results show that unit costs (exergetic and monetary) obtained for power and useful heat were different in the three methodologies. With the impossibility of defining the dissipative equipment product and fuel using total exergy, one of the strategies found by $\mathrm{E}$ Model consists in the union of dissipative with productive equipment. This option, however, reduces both the quality and the accuracy of the thermoeconomic analysis. The E Model overcharges the heat unit cost in detriment of the power unit cost when compared with the other models for the system with Extraction Condensing Steam Turbine.

For the system with Back Pressure Steam Turbine and Bypass Valve when the valve is allocated together with the turbine overcharges the power unit cost in detriment of the heat unit cost. On the other hand, when the allocation of the valve is together with the process, overcharges the heat unit cost in detriment of the power unit cost.

The localized physical exergy disaggregation, i.e., combining E Model with some other methodology that is capable of treating dissipative equipment has proved to be feasible, since it reduces the complexity of the productive structure, the computational efforts, the complexity involved in the modeling and also is consistent from the point of view of thermodynamics

\section{ACKNOWLEDGEMENTS}

The authors would like to thank the Support Foundation of Espírito Santo Research (FAPES), the Federal University of Espírito Santo (UFES), the Federal Institute of Espírito Santo (IFES), the Coordination of Improvement of Higher-Level Personnel (CAPES) and Viana S.A. Thermoelectric Power Plant - TEVISA for their financial support.

\section{REFERENCES}

Dincer, I.; Rosen, M. A. Exergy: Energy, Environment and Sustainable Development, 2013.

Erlach, B., Serra, L. and Valero, A., Structural Theory as Standard for Thermoeconomics. Energy Conversion and Management 1999;40:1627-1649.

Faria, P.R. 2014a. Uma Avaliação das Metodologias de Desagregação da Exergia Física para a Modelagem Termoeconômica de Sistemas. Dissertação de Mestrado. Universidade Federal do Espírito Santo, Brasil, 2014.

Faria, P.R., Santos, R. G., Santos, J. J. C. S. 2014b. Physical Exergy Disaggregation for Dissipative Components Disaggregation in Thermoeconomic Modeling for Cost Allocatio. In Proceedings of ENCIT 2014. Belém, PA, Brazil.

Frangopoulos, C. A. Thermoeconomic functional analysis: A method for Optimal Design or improvement of Complex Thermal Systems. Tese (Doutorado) - Georgia Institute of Technology, 1983. 
Frangopoulos, C. A. Thermo-economic functional analysis and optimization. Energy, v. 12, n. 7, p. 563-571, jan 1987. ISSN 03605442.

Lazzaretto, A.; Tsatsaronis, G. SPECO: A Systematic And General Methodology For Calculating Efficiencies And Costs In Thermal Systems. Energy, v. 31, n. 8-9, p. 1257-1289, jan 2006. ISSN 03605442.

Lourenço A.B., Santos J.J., Donatelli J.L., Thermoeconomic Modeling of a Simple Heat Pump Cycle: An Alternative Approach for Valve Isolation. In: Mitrović D., Laković M., editors. SimTerm 2011: Proceedings of the Fifteenth Symposium on Thermal Science and Engineering of Serbia; 2011 Oct 18-21; Sokobanja, Serbia. 453-446.

Lozano, M. A.; Valero, A. Thermoeconomic analysis of gas turbine cogeneration systems. ASME, NEW YORK, NY,(USA)., v. 30, p. 311-320, 1993.

Morosuk, T.; Tsatsaronis, G. A New Approach To The Exergy Analysis Of Absorption Refrigeration Machines. Energy, v. 33, n. 6, p. 890-907, jun 2008. ISSN 03605442.

Santos, J. J. C. S., Nascimento, M. A. R. and Lora, E. E. S., 2006. On The Thermoeconomic Modeling for Cost Allocation in a Dual-Purpose Power and Desalination Plant. In Proceedings of ECOS 2006. Aghia Pelagia, Crete, Greece, Vol. 1, pp. 441-448.

Santos, J. J. C. S. et al. On the Productive Structure for the Residues Cost Allocation in a Gas Turbine Cogeneration Plant. In: ECOS 2008 Proceedings of the 21st International Conference on Efficiency, Cost, Optimization, Simulation and Environmental Impact of Energy Systems. [S.1.: s.n.], 2008. v. 2, p. 641-648. ISBN 978-83-922381-4-0.

Santos, J. J. C. S. et al. On the Negentropy Application in Thermoeconomics: A Fictitious or an Exergy Component Flow? International Journal of Thermodynamics, v. 12, n. 4, p. 163-176, 2009

Torres, C., Serra, L., Valero, A. and Lozano, M.A., The Productive Structure and Thermoeconomic Theories of System Optimization. ME'96: International Mechanical Engineering Congress \& Exposition 1996 (ASME WAM' 96).

Tsatsaronis, G. Thermoeconomic Analysis And Optimization Of Energy Systems. Progress In Energy And Combustion Science, v. 19, n. 3, p. 227-257, jan 1993. ISSN 03601285.

Valero, A., Serra, L.; Uche, J., Fundamentals of Exergy Cost Accounting and Thermoeconomics. Part I: Theory. Journal of Energy Resources Technology $2006 ; 128: 1-8$. 